Article

\title{
Comparative Performance of Semi-Transparent PV Modules and Electrochromic Windows for Improving Energy Efficiency in Buildings
}

\author{
Nuria Martín-Chivelet ${ }^{1, *}$, Cecilia Guillén ${ }^{2}$ (D), Juan Francisco Trigo ${ }^{2}$, José Herrero ${ }^{2}$, \\ Juan José Pérez ${ }^{1}$ and Faustino Chenlo ${ }^{1}$ \\ 1 CIEMAT_-Building Integrated Photovoltaics Group, Avda. Complutense, 40, 28040 Madrid, Spain; \\ juanjo.perez.mail@gmail.com (J.J.P.); faustino.chenlo@ciemat.es (F.C.) \\ 2 CIEMAT-Polycrystalline Materials Group, Avda. Complutense, 40, 28040 Madrid, Spain; \\ c.guillen@ciemat.es (C.G.); juanfrancisco.trigo@ciemat.es (J.F.T.); jose.herrero@ciemat.es (J.H.) \\ * Correspondence: nuria.martin@ciemat.es; Tel.: +34-91-3466531
}

Received: 26 April 2018; Accepted: 7 June 2018; Published: 12 June 2018

\begin{abstract}
Advanced constructive materials, such as electrochromic smart windows (ECSWs) and building integrated photovoltaics modules (BIPV), can improve the energy efficiency in buildings. A good optical and thermal characterization of these elements is necessary to assess and compare their performance. The existing testing procedures for glass in buildings are applied to both types of elements, and it is considered that while the optical procedures are suitable and allow good comparison of the two technologies, the indoor thermal testing procedures are not valid for BIPV nor ECSWs, because temperature of these absorbing elements strongly depend on the irradiance, something not considered in the current standards. To show and characterize this dependence, simultaneously monitoring of different photovoltaics (PV) modules and electrochromic windows has been performed outdoors under solar irradiance. A relationship between the surface temperature, the irradiance, and the ambient temperature has been obtained for each sample to compare both technologies.
\end{abstract}

Keywords: building integrated photovoltaics (BIPV); semi-transparent photovoltaic module; smart window; electrochromic smart window; building energy efficiency; building element characterization

\section{Introduction}

In developed countries, the energy consumption of commercial and residential buildings is continuously increasing, and it has already surpassed that required in transportation and industrial sectors [1]. Buildings consume huge amounts of energy in artificial lighting and air-conditioner devices to adjust the illumination and indoor temperature of living spaces [2-5]. Windows are the most vulnerable parts to heat loss or gain in buildings, but they are also related to light comfort and biopsychological health for the occupants. Thus, advanced glazing technologies (passive and active windows) are being developed to decrease the energy demands while improving indoor environment in buildings.

According to the European Directives, the energy performance of buildings should be calculated on the basis of a methodology which considers thermal transmittance, adequate natural lighting, heating and air-conditioning installations, application of energy from renewable sources, passive heating and cooling elements, shading, indoor air quality, and design of the building [6,7]. In this energy assessment of the building, new construction elements, such as photovoltaic systems or smart windows, should also be included [8]. 
Semi-transparent PV modules (STPV) integrated into buildings become multifunctional elements of the building envelope, combining electricity generation from a renewable source with specific optical and thermal properties. STPV modules designed for building integration usually consist of a glass laminate containing photovoltaic (PV) cells made of crystalline PV silicon or a thin film PV material. The advantage of thin film technologies is that they more easily achieve nearly homogenous glazing elements.

On the other side, electrochromic smart windows (ECSWs), which change their transmittance characteristics by application of a potential across them, can modulate the amount of heat and light penetrating into the building, which directly affects the energy performance of the building $[9,10]$. Electrochromic smart glass laminate consists of two transparent glasses with an electrochromic device in between. An electric potential initiates redox reactions, transitioning the color and the transparency of the smart glass.

STPV modules and smart windows can be designed to improve the energy savings of a building. For that purpose, it is firstly necessary to characterize the optical and thermal properties of these elements, and to analyze how these properties change as a function of their design parameters, such as transparency or glazing structure. Several works can be found in the literature on the energy assessment of buildings with STPV façades [11-15] or ECSW dynamic glazing [16-18]. These studies report the best energy saving potential in each location and building type, after analyzing the influence of parameters such as the PV module transparency, the window-to-wall ratio, or the type of glass structure, ranging from single glass to multiple glazing insulated windows.

Chae et al. [11] performed the building energy simulation starting from optical measurements, and studying the impacts of optical characteristics on the overall energy performance of STPV windows. Olivieri et al. [12] evaluated the energy saving potential of different amorphous silicon STPV, considering the effect of the sample transparency and the window-to-wall ratio. The study is based on previous optical characterization of PV modules [13]. Didoné and Wagner [14] and other authors [16-18] concluded that both STPVs and ECSWs have considerable potential for reducing lighting and air-conditioning load if used with appropriate control strategies. Wang et al. [15], after validating a model with experimental data, conducted a sensitivity analysis to investigate the influence of air gap depth and rear side glass of PV insulated glass units. In these works, thermal properties of the STPV or ECSW laminates are obtained from the optical and electrical characterization and using WINDOW software [19], developed by Lawrence Berkeley National Laboratory for analyzing the performance of various glazing systems. WINDOW obtained data were exported to another software [20] for the complete simulation of the building.

While the optical characterization of STPV modules and ECSWs can be performed in a similar way as it is in glass in building, regarding luminous, solar, and color rendering properties, the thermal transmittance measurement is not so simple, as demonstrates the variety of approaches found in the related literature. The reason is the lack of specific standards for the characterization of BIPV and ECSW elements.

There are several works in the literature concerning the experimental characterization of the solar heat gain or solar factor ( $g$-value) of STPV modules, which represents the total solar energy transmitted indoors through them [21-24], but few include thermal transmittance measurements for the modules. Mazzali et al. [24] measured the thermal conductance of a double glazing STPV system with the guarded hot plate method as described in EN 674 [25] standard. The thermal conductance of the glazing has also been calculated by the analytical method described in EN 673 [26], obtaining the total thermal resistance of the double glazing system by the sum of the thermal resistance of the glass panes and the air cavity. Using the same boundary conditions as for the hot plate measurements, the thermal conductance and the $U$-value were very similar.

A recent European Standard, the EN 50583 "Photovoltaics in buildings" [27], focuses on the properties of BIPV modules relevant to essential building requirements. However, some aspects as the thermal performance are not updated, but they are redirected to the previous "Glass in building" standards EN 673, EN 674, or EN 675, equivalent to the international ISO 10291, ISO 10292, and ISO 
10293, respectively. These standards are not adapted to PV modules, because assuming similitude of PV laminates with glazing becomes incorrect when dealing with the temperature performance of the element, especially due to the solar irradiance sensibility (due to absorptivity) of PV modules in comparison to glazing elements. The same can be applied to ECSWs. Temperature differences compared to glazing cause differences in the thermal transmittance properties of the considered elements, and consequently, in the building energy performance.

This paper aims at progressing in the characterization of STPV modules and ECSWs, regarding their optical and thermal properties. Indoor measurements have shown that the conductivity of these advanced elements under no irradiance is similar to that of equivalent conventional glazing, but temperatures at real operating conditions become quite different. A first simple approach to the dependence of the temperature of each technology with the irradiance is included, leading to a nominal effective temperature, after outdoor monitoring during several clear days. These nominal values allow the comparison of the strength of the relationship between irradiance and element temperature in each case.

\section{Approach}

The samples considered are seven glass-laminate STPV modules based on amorphous silicon with two different types of encapsulant, ethylene-vinyl acetate (EVA) or polyvinyl butyral (PVB), and having different transparency degrees (from 0 to 33\%), and two ECSW laminates based on electrochromic materials, connected to an electrical controller that allows five different charge levels, from the clearest state (assigned to level L1) to the darkest one (level L5) passing through intermediate states. These PV and EC laminates have been used for the optical characterization, while some double-glazing structures have been also considered for the thermal characterization. They are listed in Table 1, according to their different constituents (from outside to inside):

- PV laminate $(7.16 \mathrm{~mm}): 3.2 \mathrm{~mm}$ float glass + a-Si thin film solar cells + 0.76 PVB/EVA foils + $3.2 \mathrm{~mm}$ float glass. These samples are identified as "PV_a\#", if the encapsulant is EVA, and "PV_b\#", if the encapsulant is PVB, being \# the light transmittance in percentage.

- PV double glazing $(27.16 \mathrm{~mm}): 3.2 \mathrm{~mm}$ float glass + a-Si thin film solar cells $+0.76 \mathrm{~mm}$ PVB $/ E V A$ foils $+3.2 \mathrm{~mm}$ float glass $+16 \mathrm{~mm}$ space between panes $+4 \mathrm{~mm}$ float glass. These samples are identified as "PV_a\# (dg-16)" or "PV-b\# (dg-16)".

- EC laminate $(9 \mathrm{~mm}): 4 \mathrm{~mm}$ float glass $+1 \mathrm{~mm}$ electrochromic device (thin-film electrodes and electrochromic materials between them) $+4 \mathrm{~mm}$ float glass. These samples are identified as "SW_L\#", where \# refers to the state of the electrochromic device.

- EC double glazing ( $29 \mathrm{~mm}$ ): $9 \mathrm{~mm}$ electrochromic laminated glass $+16 \mathrm{~mm}$ space between the panes $+4 \mathrm{~mm}$ inside float glass pane with heat protection coating. These samples are identified as "SW_L\# (dg-16)".

Table 1. Description of the photovoltaic (PV) modules and electrochromic (EC) windows analyzed in this work. Two conventional float glass double glazing were included for comparison.

\begin{tabular}{|c|c|c|}
\hline Device Structure (Single Glazing) & Transmittance & Name \\
\hline \multirow{4}{*}{ glass $(3.2 \mathrm{~mm}) / \mathrm{aSi} / \mathrm{EVA}(0.76 \mathrm{~mm}) /$ Glass $(3.2 \mathrm{~mm})$} & $0 \%$ & PV_a0 \\
\hline & $5 \%$ & PV_a5 \\
\hline & $10 \%$ & PV_a10 \\
\hline & $15 \%$ & PV_a15 \\
\hline \multirow{3}{*}{ glass $(3.2 \mathrm{~mm}) / \mathrm{aSi} / \mathrm{PVB}(0.76 \mathrm{~mm}) /$ glass $(3.2 \mathrm{~mm})$} & $0 \%$ & PV_b0 \\
\hline & $12 \%$ & PV_b12 \\
\hline & $33 \%$ & PV_b33 \\
\hline \multirow{5}{*}{ glass $(4 \mathrm{~mm}) / \mathrm{EC}(1 \mathrm{~mm}) /$ glass $(4 \mathrm{~mm})$} & Level 1 & SW_L1 \\
\hline & Level 2 & SW_L2 \\
\hline & Level 3 & SW_L3 \\
\hline & Level 4 & SW_L4 \\
\hline & Level 5 & SW_L5 \\
\hline
\end{tabular}


Table 1. Cont.

\begin{tabular}{ccc}
\hline Device Structure (Double Glazing) & Transmittance & Name \\
\hline glass $(3.2 \mathrm{~mm}) / \mathrm{aSi} / \mathrm{EVA}(0.76 \mathrm{~mm}) /$ glass $(3.2 \mathrm{~mm}) /$ spacer $(16 \mathrm{~mm}) /$ glass $(4 \mathrm{~mm})$ & $0 \%$ & PV_a0(dg_16) \\
\hline \multirow{2}{*}{ glass $(3.2 \mathrm{~mm}) / \mathrm{aSi} / \mathrm{PVB}(0.76 \mathrm{~mm}) /$ glass $(3.2 \mathrm{~mm}) /$ spacer $(16 \mathrm{~mm}) /$ glass $(4 \mathrm{~mm})$} & $0 \%$ & PV_b0(dg_16) \\
\hline glass $(4 \mathrm{~mm}) / \mathrm{EC}(1 \mathrm{~mm}) /$ glass $(4 \mathrm{~mm}) /$ spacer $(16 \mathrm{~mm}) /$ glass $(4 \mathrm{~mm})$ & Level 1 & SW_b30(dg_16) \\
\hline glass $(4 \mathrm{~mm}) /$ spacer $(16 \mathrm{~mm}) /$ glass $(4 \mathrm{~mm})$ & Level 5 & SW_L5 $($ dg_16) \\
glass $(4 \mathrm{~mm}) /$ spacer $(24 \mathrm{~mm}) /$ glass $(4 \mathrm{~mm})$ & & FG(dg_16) \\
\hline
\end{tabular}

The optical characterization of the PV modules and of the electrochromic smart windows follows the methodology suggested by [13] for semi-transparent PV modules, based on the standard EN 410 [28], which is also the document considered in EN 50583. The standard, which is equivalent to the international ISO 9050, specifies the methodology for determining the luminous and solar characteristics of glazing in buildings, allowing the comparison of different types of elements. The calculation of the color rendering indices of the samples is based on the International Commission on illumination's procedure [29]. To obtain the luminous and solar characteristics, the transmittance and reflectance spectra have been determined (measurement error $\pm 1 \%$ ) in the wavelength range of 250 to $2500 \mathrm{~nm}$ (see Figure 1), with a Perkin Elmer ${ }^{\circledR}$ Lambda $900 \mathrm{UV} /$ vis/NIR spectrophotometer equipped with an integrating sphere.

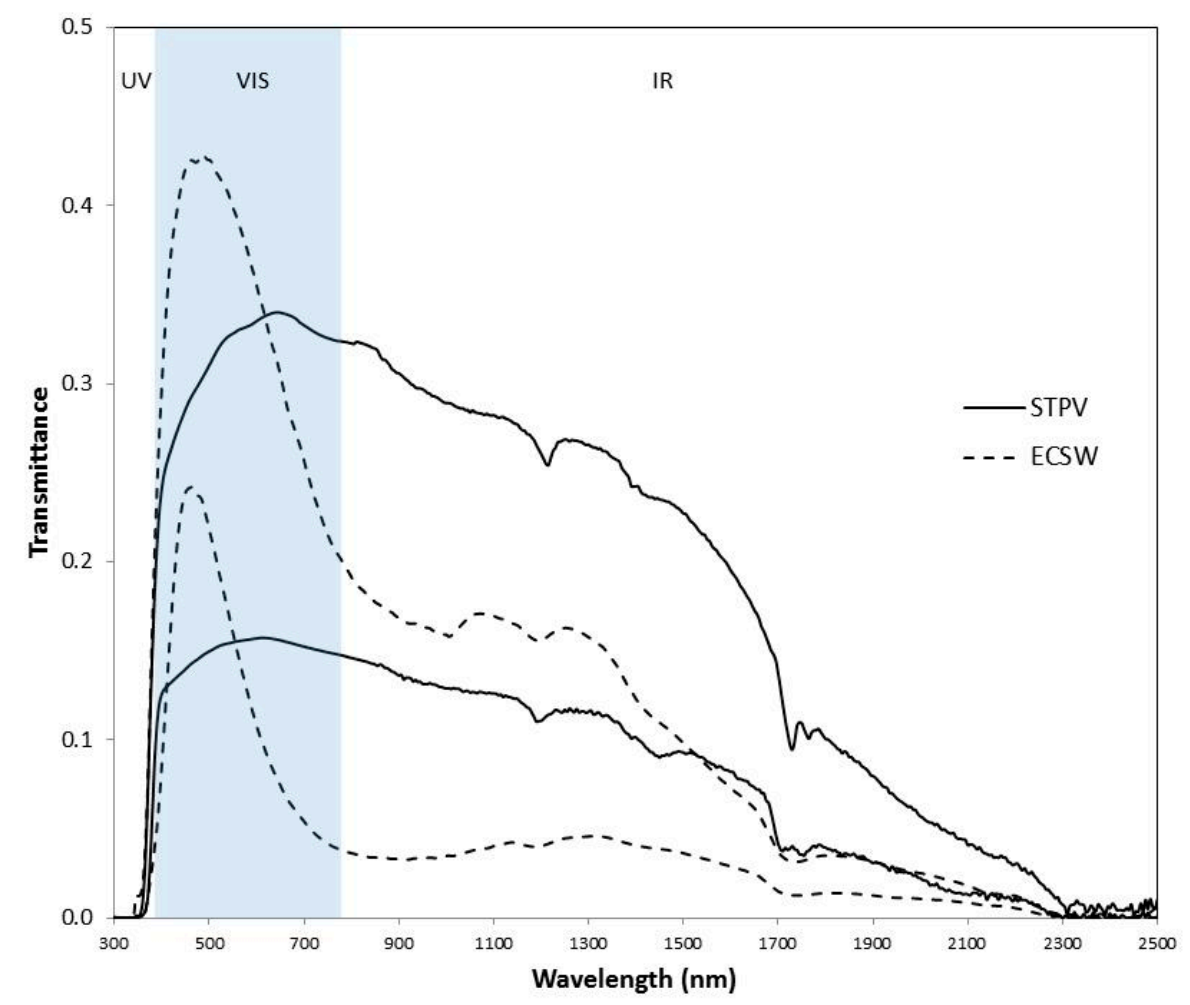

Figure 1. Spectral transmittance curves of two semi-transparent PV (STPV) samples and one electrochromic smart window (ECSW) at different charge levels. Notice the different weight in visible and infrared ranges for each technology.

On the other side, the thermal behavior has been analyzed indoors, according to the recommendations of the standard EN 50583 regarding measurement and calculation of the thermal transmittance or global heat transfer coefficient ( $U$-value) of BIPV modules. The $U$-value is a measure 
of the heat transmission through a building element, with lower numbers indicating better insulating properties (Equation (1)). One of the standards referred in EN 50583 for the determination of thermal transmittance for glass in building is the European EN 673. It specifies a calculation method to determine the center-of-glass thermal transmittance of glazing, and includes standard values for the external $\left(h_{\mathrm{e}}\right)$ and internal $\left(h_{\mathrm{i}}\right)$ surface film coefficients, to obtain comparable $U$-values. The method is based on the determination of the total conductance of the glazing, which is result of the contribution of each glazing layer and each glazing cavity. It has been measured with a calorimeter and six ultrathin CAPTEC ${ }^{\circledR}$ heat flux sensors with thermocouples (measurement error $\pm 10 \%$ ) and some other additional type $\mathrm{T}$ thermocouples. The calorimeter is an adiabatic box with a heater plate covering the whole background internal wall. The heat comes out of the box through the sample, in vertical position and at steady-state conditions, and the total thermal conductance $h_{\mathrm{t}}$ is calculated following the Fourier's law in one dimension (Equation (2)):

$$
\begin{gathered}
1 / U=\left(1 / h_{e}\right)+\left(1 / h_{t}\right)+\left(1 / h_{i}\right), \\
q_{x}=-h_{t} \cdot \Delta T,
\end{gathered}
$$

where $h_{\mathrm{i}}$ and $h_{\mathrm{e}}$ are the internal and external heat transfer coefficients, respectively, being $h_{\mathrm{i}}=7.7 \mathrm{~W} / \mathrm{m}^{2} \mathrm{~K}$ and $h_{\mathrm{e}}=25.0 \mathrm{~W} / \mathrm{m}^{2} \mathrm{~K}$, the standard values according to EN $673, q_{x}$ is the density of heat flux rate $\left(\mathrm{W} / \mathrm{m}^{2}\right), \Delta T$ the temperature difference between the two surfaces, and $h_{\mathrm{t}}$ the total element's conductance. The method does not consider the influence of solar radiation absorption on the thermal transmittance, and so it is only valid under no solar irradiance in the case of PV modules and electrochromic windows.

Additionally, the irradiance-temperature dependence of each sample has been quantified outdoors, following a method similar to the one described in IEC 61646 [30] for the nominal operating cell temperature of amorphous silicon PV modules. The method has been chosen because of its simplicity, although the temperatures of the samples depend on the boundary conditions, and would increase some degrees if the rear side of the elements is not well ventilated or the tilt angle increases. Choosing this experimental set-up has allowed all samples to be tested outdoors simultaneously for a better comparison, see Figure 2 .

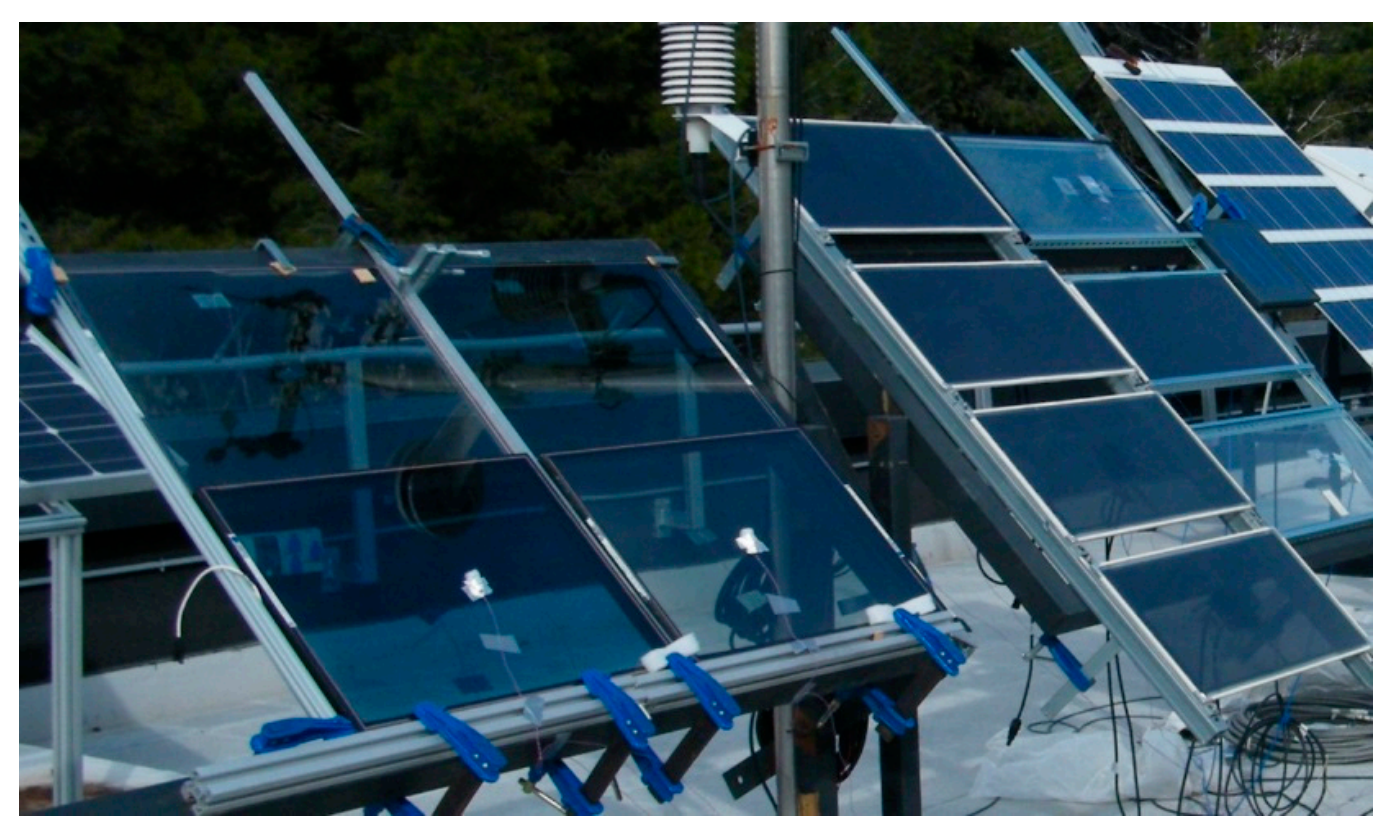

Figure 2. Outdoor experimental set-up of different STPV and ECSW samples. Surface temperature is measured with thermocouples on the back surface in all cases, except in the double-glazing samples. 


\section{Results and Discussion}

\subsection{Lighting and Solar Performance}

From the spectral transmittance $T(\lambda)$ and reflectance $R(\lambda)$ measurements, the following parameters have been obtained:

- Visible light transmittance and reflectance $\left(\tau_{\mathrm{v}}, \rho_{\mathrm{v}}\right)$, which represent the fraction of the incident light coming from a D65 daylight standard illuminant that is transmitted or reflected by the glazing and viewed by a standard photopic observer $V(\lambda)$ assumed as reference.

$$
\tau_{\mathrm{V}}(\alpha)=\frac{\sum_{\lambda} T(\lambda, \alpha) \cdot D 65(\lambda) \cdot V(\lambda) \Delta \lambda}{\sum_{\lambda} D 65(\lambda) \cdot V(\lambda) \Delta \lambda}, \rho_{\mathrm{V}}(\alpha)=\frac{\sum_{\lambda} R(\lambda, \alpha) \cdot D 65(\lambda) \cdot V(\lambda) \Delta \lambda}{\sum_{\lambda} D 65(\lambda) \cdot V(\lambda) \Delta \lambda}
$$

- Solar direct transmittance and reflectance $\left(\tau_{\mathrm{e}}, \rho_{\mathrm{e}}\right)$, which represent the fraction of the incident solar radiation (from 300 to $2500 \mathrm{~nm}$ ) that is transmitted or reflected by the glazing, weighted by the standard solar spectral irradiance $S(\lambda)$.

$$
\tau_{\mathrm{e}}(\alpha)=\frac{\sum_{\lambda} T(\lambda, \alpha) \cdot S(\lambda) \Delta \lambda}{\sum_{\lambda} S(\lambda) \Delta \lambda}, \rho_{\mathrm{e}}(\alpha)=\frac{\sum_{\lambda} R(\lambda, \alpha) \cdot S(\lambda) \Delta \lambda}{\sum_{\lambda} S(\lambda) \Delta \lambda}
$$

- Solar factor (or $g$-value), which represents the total solar energy transmitted indoors through the glazing, both by direct transmission and by indoor emission of part of the absorbed energy:

$$
g=\tau_{e}+\alpha_{e} h_{i} /\left(h_{i}+h_{e}\right)
$$

where $\alpha_{\mathrm{e}}$ is the solar direct absorptance, calculated as $\alpha_{\mathrm{e}}=1-\tau_{\mathrm{e}}-\rho_{\mathrm{e}}$, and $h_{\mathrm{i}}$ and $h_{\mathrm{e}}$ are the internal and external heat transfer coefficients, respectively, being $h_{\mathrm{i}}=7.7 \mathrm{~W} / \mathrm{m}^{2} \mathrm{~K}$ and $h_{\mathrm{e}}=25.0 \mathrm{~W} / \mathrm{m}^{2} \mathrm{~K}$ the standard values according to EN 673. Shading coefficient (SC), which compares the $g$-value of the tested sample with that of a standard 3-4 $\mathrm{mm}$ thick float glass, $S C=g / 0.87$.

- $\quad$ Selectivity index $(S)$, which compares the light transmittance with the solar factor $\left(S=\tau_{\mathrm{v}} / g\right)$. High selectivity index indicates good solar control and high light transmission.

- Color rendering index $(C R I)$, which indicates the accuracy in the colors reproduction through the glazing. It is considered good color rendering if $0.60 \leq C R I \leq 0.79$ and excellent if $C R I \geq 0.80$.

The optical parameters obtained for the various samples are compared in Figure 3 and Table 2. Maximum visible transmittance $\left(\tau_{\mathrm{V}}=0.65\right)$ is achieved by the ECSW in the bleached state, which has also the highest solar factor $(g=0.59)$, considering these values suitable for windows in cool and temperate climates [31]. It can be observed that g decreases linearly with transparency (visual transmittance) in all cases, approaching the most suitable values for windows in hot climates $(g<0.40)$ [31]. For a fixed transparency value, ECSWs show about $15 \%$ lower $g$-values than STPV for a luminous transmittance of 0.30 , and almost $10 \%$ lower for a luminous transmittance of 0.15 (see Figures 1 and 3). As a consequence, the shading coefficient is proportionally higher in ECSW than in STPV in the studied range: for the samples considered, it varies from 0.32 to 0.68 in ECSW and from 0.24 to 0.48 in STPV. For the same reason, the selectivity index is higher in ECSW than in STPV for the equal luminous transmittance: an increase of $10 \%$ for $\tau_{\mathrm{v}}=0.30$ and of $12 \%$ for $\tau_{\mathrm{v}}=0.15$.

The contrast ratio for the ECSW is 5:1, as calculated from the solar transmittance values obtained for the bleached state and the darkest one. In this sense, several computational studies have shown that contrast ratios ranging between 5:1 and 10:1 are able to provide significant energy saving compared to conventional glazing [32-34]. However, this trend cannot be directly extrapolated to higher contrast ratios, because the solar factor is not significantly reduced, and the cooling load reduction benefits may be surpassed by the increase in lighting requirements. 
Regarding color reproducibility, STPV modules show excellent color rendering indices in all cases, ( 0.97 or 0.96 , depending on the encapsulant type), independently of the transparency of the PV module. ECSW samples show variable CRIs, function of the luminous transparency of the laminate, achieving excellent values also the three most transparent of them $(C R I \geq 0.88)$ and decreasing to good values $(0.60 \leq C R I \leq 0.79)$ if light transparency values are under 0.29 (see Figure 3 ). It should be noted that color rendering can be maintained in the excellent range by combining several dark SWs with some other SWs in the highest transmittance states [35].

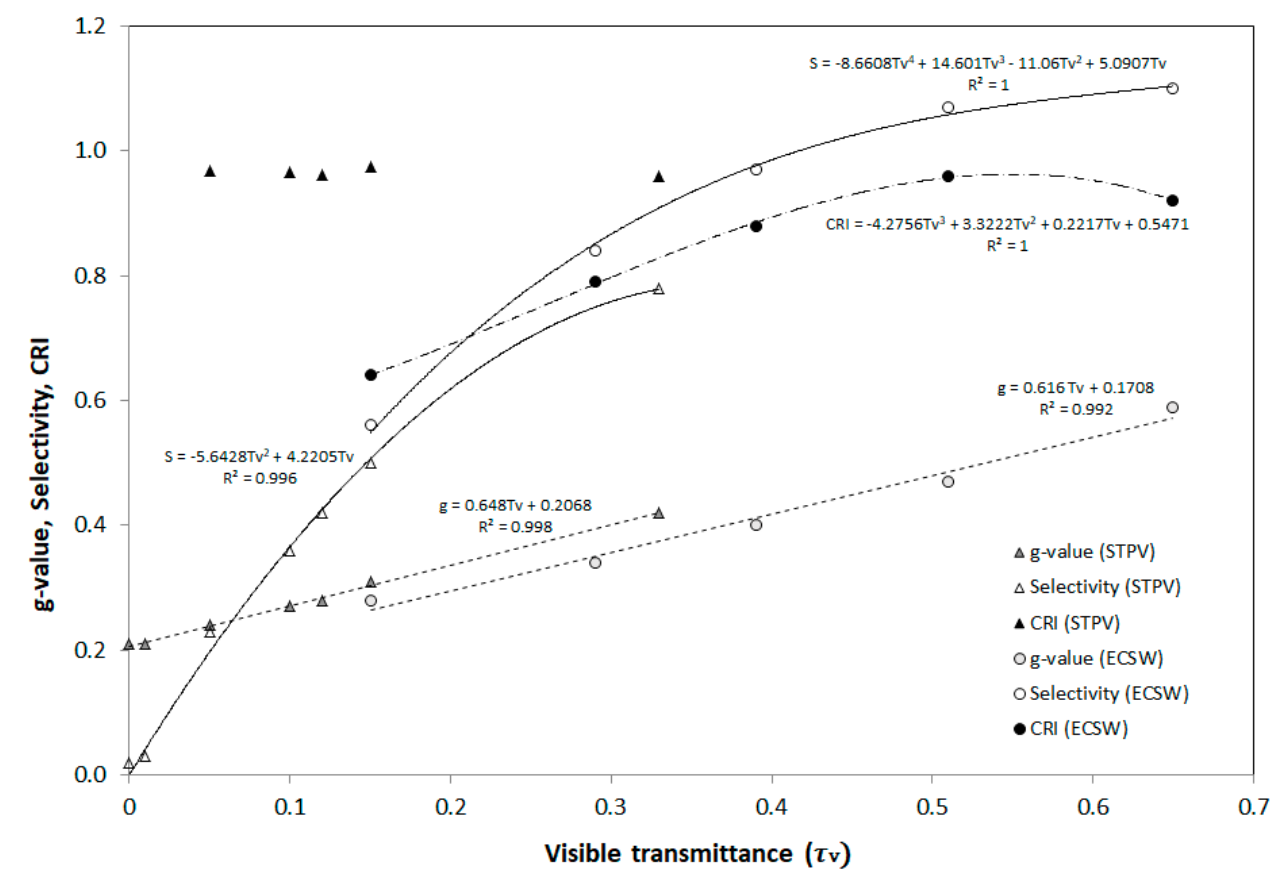

Figure 3. Solar factor, selectivity index, and color rendering index of all the tested samples, plotted versus the visible transmittance. A polynomial regression is plotted for each set of data, except for color rendering index (CRI) (STPV), where nearly constant values are obtained independently of the transparency.

Table 2. Optical parameters obtained for the STPV modules and the ECSW at different charge levels, obtained with the spectral transmittance and considering the standards [28,29].

\begin{tabular}{ccccccccccccc}
\hline & PV_a0 & PV_a5 & PV_a10 & PV_a15 & PV_b0 & PV_b12 & PV_b33 & SW_L1 & SW_L2 & SW_L3 & SW_L4 & SW_L5 \\
\hline$\tau_{\mathrm{v}}$ & 0.00 & 0.05 & 0.10 & 0.15 & 0.01 & 0.12 & 0.33 & 0.65 & 0.51 & 0.39 & 0.29 & 0.15 \\
$\rho_{\mathrm{v}}$ & 0.07 & 0.08 & 0.07 & 0.07 & 0.08 & 0.07 & 0.08 & 0.11 & 0.09 & 0.08 & 0.08 & 0.08 \\
$\tau_{\mathrm{e}}$ & 0.00 & 0.05 & 0.08 & 0.13 & 0.00 & 0.10 & 0.28 & 0.51 & 0.35 & 0.25 & 0.18 & 0.09 \\
$\rho_{\mathrm{e}}$ & 0.12 & 0.13 & 0.12 & 0.12 & 0.14 & 0.12 & 0.11 & 0.13 & 0.12 & 0.11 & 0.11 & 0.11 \\
$\alpha_{\mathrm{e}}$ & 0.87 & 0.82 & 0.80 & 0.76 & 0.86 & 0.79 & 0.61 & 0.36 & 0.53 & 0.64 & 0.72 & 0.81 \\
$g$ & 0.21 & 0.24 & 0.27 & 0.31 & 0.21 & 0.28 & 0.42 & 0.59 & 0.47 & 0.40 & 0.34 & 0.28 \\
$S C$ & 0.24 & 0.28 & 0.31 & 0.35 & 0.24 & 0.33 & 0.48 & 0.68 & 0.54 & 0.46 & 0.40 & 0.32 \\
$S$ & 0.02 & 0.23 & 0.36 & 0.50 & 0.03 & 0.42 & 0.78 & 1.10 & 1.07 & 0.97 & 0.84 & 0.56 \\
$C R I$ & - & 0.97 & 0.97 & 0.97 & - & 0.96 & 0.96 & 0.92 & 0.96 & 0.88 & 0.79 & 0.64 \\
\hline
\end{tabular}

\subsection{Indoors Thermal Testing}

Table 3 shows the $U$-value calculated as indicated in EN 673 for glazing, after testing the total thermal conductance of each sample. Standard glasses are also included for validation of the testing procedure and comparison. It is found that thermal conductance of STPV and ECSW is mainly determined by the glazing characteristics of their constituents, the thickness of the glasses, and the air gap, in the case of double glazing, being the most determinant factors. Furthermore, it can be observed that the transparency degree of the PV modules and the smart windows has no appreciable influence on the thermal conductance. It should be noted that $U$-values below $4.0 \mathrm{~W} / \mathrm{m}^{2} \mathrm{~K}$ are considered 
suitable for windows (glass and frame) in hot climates [31,36], but more restrictive limits are imposed for temperate and cool regions, $U<2.5 \mathrm{~W} / \mathrm{m}^{2} \mathrm{~K}$ and $U<2.0 \mathrm{~W} / \mathrm{m}^{2} \mathrm{~K}$, respectively [31,36].

Table 3. $U$-value of some of the samples, calculated from heat conductance measurements at the laboratory and considering EN 673 method. Two conventional double glasses (FG) were also measured for comparison.

\begin{tabular}{cccccccc}
\hline & FG (dg_16) & FG (dg_24) & PV_a0 & $\begin{array}{c}\text { PV_b0 } \\
\left(\mathbf{d g} \_\mathbf{1 6}\right)\end{array}$ & $\begin{array}{c}\text { PV_b30 } \\
\left(\mathbf{d g} \_\mathbf{1 6}\right)\end{array}$ & SW_L1/SW_L5 & $\begin{array}{c}\text { SW_L1/SW_L5 } \\
\left(\mathbf{d g} \_ \text {16) }\right.\end{array}$ \\
\hline$U$-value $\left(\mathrm{W} / \mathrm{m}^{2} \mathrm{~K}\right)$ & 2.8 & 2.9 & 5.1 & 2.8 & 2.8 & 5.0 & 1.4 \\
Std. Error $\left(\mathrm{W} / \mathrm{m}^{2} \mathrm{~K}\right)$ & 0.2 & 0.2 & 0.2 & 0.4 & 0.4 & 0.2 & 0.2 \\
\hline
\end{tabular}

\subsection{Outdoors Thermal Testing}

The temperature of the samples has also been measured in real operating conditions, testing all the samples outdoors simultaneously for comparison. A simple relationship between the irradiance, the ambient temperature and the temperature of the PV modules, according to the Standard IEC 61646 for the measurement of the nominal operating cell temperature of thin film PV modules, has been applied to all the samples to obtain a nominal temperature in each case:

$$
T_{s}=T_{a}+G \cdot\left(T_{N}-20\right) / 800,
$$

where all temperatures are in ${ }^{\circ} \mathrm{C}, T_{s}$ is the surface temperature, $T_{a}$ the ambient temperature, $G$ the solar irradiance, and $T_{N}$ a constant value to be fitted in each case, named as the nominal temperature at $G=800 \mathrm{~W} / \mathrm{m}^{2}$ and $T_{a}=20^{\circ} \mathrm{C}$. The testing campaign for the determination of the operating temperature of each sample has been carried out during 5 different clear days, from April to June. Every $30 \mathrm{~s}$, solar irradiance, ambient temperature, wind speed, and wind direction values have been recorded with a data-logger, together with the temperature of each sample. Values of irradiance, wind speed, and wind direction are used to reject data outside the limits, as indicated in the standard, or to correct the final nominal temperature values. Data of $\left(T_{s}-T_{a}\right)$ plotted versus the irradiance are shown in Figure 4. In each case, the points are fitted to a linear regression, described by Equation (6), to obtain the nominal temperatures.

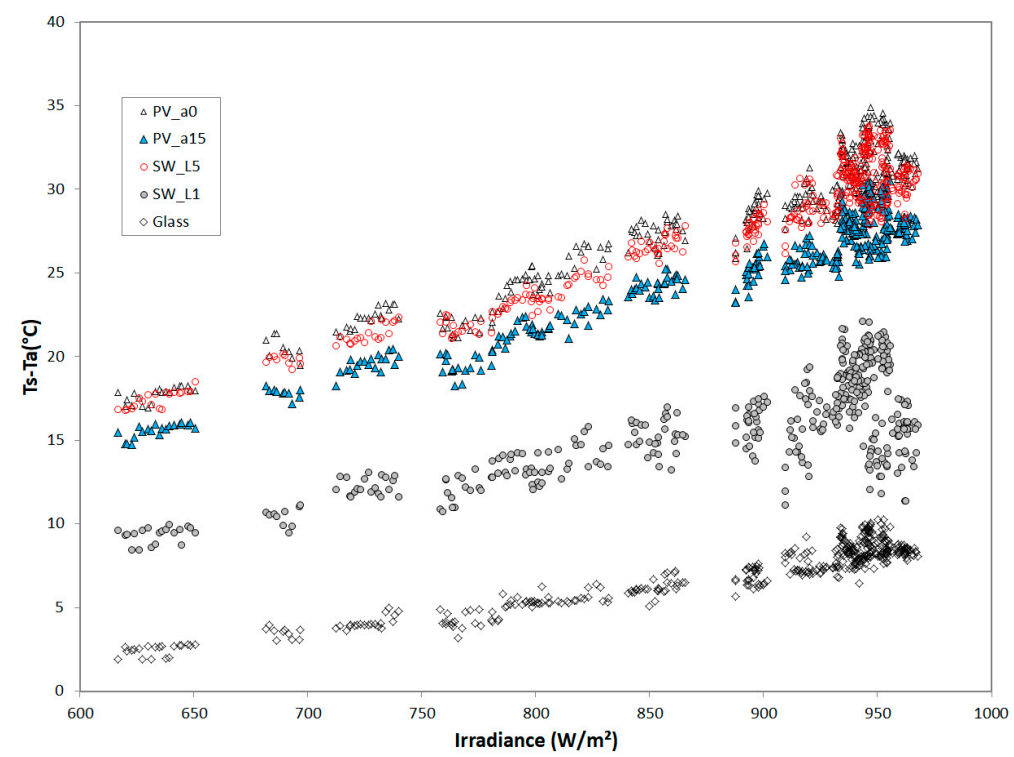

Figure 4. Temperature differences between the surface of the sample and the ambience, plotted versus solar irradiance. Values are fitted to Equation (6), the linear regression, to obtain the nominal temperatures. Fitting results are shown in Table 4. 
Table 4 shows the nominal temperatures obtained for some different samples. The fitting results of the temperature data to the model (Equation (6)) are good for all STPV and ECSW samples (for the bleached state, they are just acceptable), which explains the fact that temperature increases due to the absorption of part of the incident solar irradiance. The maximum temperature achieved by the ECSW in the dark state is low in comparison with similar electrochromic windows [37,38], and this is attributed to a lower absorption in the visible and infrared regions for the present case. Equation (6) allows estimating the surface temperature of each element under real operating conditions, once the $T_{N}$ parameter is obtained and knowing the irradiance and the ambient temperature values. The comparison of these data with those included in Table 2 proves that the $T_{N}$ value increases as the solar absorptance $\alpha_{\mathrm{e}}$ does. The irradiance dependence of the temperatures of STPV and ECSW elements should be considered at the boundary conditions, together with the ambient temperature and wind speed, for the correct determination of the heat transfer coefficients $\left(h_{\mathrm{i}}, h_{\mathrm{e}}\right)$ under real operating conditions. This is also applicable to the $g$-value calculation by means of Equation (5), where $h_{\mathrm{i}}, h_{\mathrm{e}}$ should be corrected for real operating conditions.

The authors suggest measuring the thermal properties of BIPV modules and ECSW under at least four different solar irradiance levels at stationary conditions. This can be made by integrating the BIPV modules or ECSW as windows in a testing cell, where irradiance, indoor and outdoor temperatures, and wind speed and direction can be monitored at a testing facility that is being developed at CIEMAT. Alternatively, Passys cells [39] can be used to obtain a dynamic thermal and solar performance of the elements under real operating conditions, a test that would take some months. This paper does not address this characterization, but it is the intention in the near future.

Table 4. The nominal operating temperature of four different samples, coefficient of determination and standard deviation in each case.

\begin{tabular}{ccccc}
\hline & PV_a0 & PV_a15 & SW_L5 & SW_L1 \\
\hline $\boldsymbol{T}_{\boldsymbol{N}}\left({ }^{\circ} \mathbf{C}\right)$ & 45.8 & 42.8 & 45.2 & 34.4 \\
$\mathbf{R}^{\mathbf{2}}$ & 0.85 & 0.85 & 0.84 & 0.54 \\
$\boldsymbol{\sigma}\left({ }^{\circ} \mathbf{C}\right)$ & 1.6 & 1.4 & 1.6 & 2.0 \\
\hline
\end{tabular}

\section{Conclusions}

This paper addresses the characterization of electrochromic smart windows (ECSWs) and semi-transparent photovoltaic modules (STPV) for building integration, from the optical and thermal points of views. The methodology has been applied to compare the performance of both types of glazing systems. They have shown interesting features as efficient glazing elements, as their relationship between transparency and solar factor, showing their daylight and solar modulating possibilities, or their good color-rendering properties. This allows selecting the desired optical transparency, with the advantage of converting part of the income irradiance into electrical power (PV modules) or effectively controlling the solar irradiance (ECSW), which improves the overall building energy balance.

The electrochromic smart windows can easily modulate their properties on site, as requested by the building needs. The solar factor varies from 0.59 (blanched state) to 0.28 (darkest state). In parallel, their visible transmittance is modulated, also, leading to high selectivity values (from 0.56 to 1.1), a good feature for the building efficiency because it allows high daylight levels with a heating control. Also, the different STPV samples allow a variety of $g$-values (from 0.21 to 0.42 ) and light transmittance (from 0 to 0.33 ), and the selectivity values vary in a wide range (from 0 to 0.78 ). The samples show excellent color rendering indexes in most cases, all PV modules having 0.96 or 0.97 , and the three most transparent EC windows having values above 0.88. By contrast, SW_L4 and SW_L5 decrease the color rendering indices to 0.79 and 0.64 , respectively. While in PV modules, color properties do not depend on the transparency, they do in EC windows: the lower the transparency, the lower the color rendering index. 
Regarding the thermal behavior, all STPV and ECSWs have shown total thermal conductance values similar to those of the equivalent conventional glazing, tested indoors with a calorimeter. According to the glass in building standard EN 673, the $U$-values of the STPV and ECSW samples would be very similar to the $U$-values of their equivalent glazings in standard conditions without irradiance. However, this would not be correct in real operating conditions, because of the irradiance dependence of the temperature of PV modules and electrochromic windows, and the subsequent influence on the internal and external heat transfer coefficient values, $h_{\mathrm{i}}$ and $h_{\mathrm{e}}$.

A simple model fitting has been used to easily estimate and compare the influence of the irradiance on the temperature of each sample. After an outdoors testing campaign, it is obtained that the operating temperature of the STPV and ECSW is differently affected by the solar irradiance. A nominal temperature has been obtained for each sample, showing that the most opaque samples (PV_a0, PV_b0, SW_L5) behave very similarly regarding temperature, achieving the highest $T_{N}$ values among all the samples $\left(45.9^{\circ} \mathrm{C}\right.$ the STPV, and $45.2{ }^{\circ} \mathrm{C}$ the ECSW). The determination of $T_{N}$ in each case allows the estimation of the surface temperature under irradiance of all the considered STPV and ECSW elements. The best fitting results to the model are obtained for the PV samples and for ECSW at the darkest level.

The authors consider that specific standards for the measurement of the solar and thermal properties of PV modules for building integration and smart windows should be developed, considering that the temperature of these elements is a function of the solar irradiance. Although from the optical point of view, the available standards for glass in buildings are suitable, it is not the case for the thermal performance. In the case of PV modules, the thermal and the solar performance are also affected by the electrical operating conditions, from open circuit to maximum power, something to consider also in the future testing procedures.

Author Contributions: Conceptualization, N.M.-C. and C.G.; Methodology, N.M.-C. and F.C.; Software, J.F.T.; Validation, C.G. and J.J.P.; Formal Analysis, C.G.; Investigation, J.J.P. and N.M.-C.; Resources, J.H.; Writing-Original Draft Preparation, N.M.-C.; Writing-Review \& Editing, C.G.; Visualization, J.F.T., J.J.P.; Supervision, J.H. and F.C.; Funding Acquisition, J.F.T.

Funding: This work has been financially supported by the OMEGA-CM program, with reference S2013/MAE2835 (within the call "Tecnologías 2013"), which is a multidisciplinary R\&D program funded by the Madrid Regional Government, co-financed by EU Structural Funds (http:/ / projects.ciemat.es/web/omega-cm/). The authors wish to express their gratitude for this support.

Conflicts of Interest: The authors declare no conflict of interest. The funding sponsors had no role in the design of the study; in the collection, analyses, or interpretation of data; in the writing of the manuscript, and in the decision to publish the results.

\section{References}

1. Pérez-Lombard, L.; Ortiz, J.; Pout, C. A review on buildings energy consumption information. Energy Build. 2008, 40, 394-398. [CrossRef]

2. Krarti, M.; Dubey, K. Benefits of energy efficiency programs for residential buildings in Bahrain. J. Build. Eng. 2018, 18, 40-50. [CrossRef]

3. Amirkhani, M.; Garcia-Hansen, V.; Isoardi, G.; Allan, A. An energy efficient lighting design strategy to enhance visual comfort in offices with windows. Energies 2017, 10, 1126. [CrossRef]

4. Salvadori, G.; Fantozzi, F.; Rocca, M.; Leccese, F. The energy audit activity focused on the lighting systems in historical buildings. Energies 2016, 9. [CrossRef]

5. Valancius, R.; Jurelionis, A.; Dorosevas, V. Method for cost-benefit analysis of improved indoor climate conditions and reduced energy consumption in office buildings. Energies 2013, 6, 4591-4606. [CrossRef]

6. EU Directive 2010/31/EU of the European Parliament and of the Council of 19 May 2010 on the energy performance of buildings. Off. J. Eur. Union 2010, L153, 13-35.

7. EU Directive 2012/27/EU of the European Parliament and of the Council of 25 October 2012 on energy efficiency. Off. J. Eur. Union 2012, L315, 1-56.

8. Rezaei, S.D.; Shannigrahi, S.; Ramakrishna, S. A review of conventional, advanced, and smart glazing technologies and materials for improving indoor environment. Sol. Energy Mater. Sol. Cells 2017, 159, $26-51$. [CrossRef] 
9. Fernandes, L.L.; Lee, E.S.; Ward, G. Lighting energy savings potential of split-pane electrochromic windows controlled for daylighting with visual comfort. Energy Build. 2013, 61, 8-20. [CrossRef]

10. Dussault, J.M.; Gosselin, L. Office buildings with electrochromic windows: A sensitivity analysis of design parameters on energy performance, and thermal and visual comfort. Energy Build. 2017, 153, 50-62. [CrossRef]

11. Chae, Y.T.; Kim, J.; Park, H.; Shin, B. Building energy performance evaluation of building integrated photovoltaic (BIPV) window with semi-transparent solar cells. Appl. Energy 2014, 129, 217-227. [CrossRef]

12. Olivieri, L.; Caamaño-Martín, E.; Moralejo-Vázquez, F.J.; Martín-Chivelet, N.; Olivieri, F.; Neila-Gonzalez, F.J. Energy saving potential of semi-transparent photovoltaic elements for building integration. Energy 2014, 76, 572-583. [CrossRef]

13. Moralejo-Vázquez, F.J.; Martín-Chivelet, N.; Olivieri, L.; Caamaño-Martín, E. Luminous and solar characterization of PV modules for building integration. Energy Build. 2015, 103, 326-337. [CrossRef]

14. Leite Didoné, E.; Wagner, A. Semi-transparent PV windows: A study for office buildings in Brazil. Energy Build. 2013, 67, 136-142. [CrossRef]

15. Wang, M.; Peng, J.; Li, N.; Lu, L.; Ma, T.; Yang, H. Assessment of energy performance of semi-transparent PV insulating glass units using a validated simulation model. Energy 2016. [CrossRef]

16. DeForest, N.; Shehabi, A.; Selkowitz, S.; Milliron, D.J. A comparative energy analysis of three electrochromic glazing technologies in commercial and residential buildings. Appl. Energy 2017, 192, 95-109. [CrossRef]

17. Tavares, P.; Bernardo, H.; Gaspar, A.; Martins, A. Control criteria of electrochromic glasses for energy savings in mediterranean buildings refurbishment. Sol. Energy 2016, 134, 236-250. [CrossRef]

18. Dussault, J.M.; Sourbron, M.; Gosselin, L. Reduced energy consumption and enhanced comfort with smart windows: Comparison between quasi-optimal, predictive and rule-based control strategies. Energy Build. 2016, 127, 680-691. [CrossRef]

19. Windows \& Daylighting. Available online: https://windows.lbl.gov/software/window (accessed on 15 March 2018).

20. Energy Plus. Available online: https:/ / energyplus.net/ (accessed on 16 February 2018).

21. Asdrubali, F.; Baldinelli, G. Thermal transmittance measurements with the hot box method: Calibration, experimental procedures, and uncertainty analyses of three different approaches. Energy Build. 2011, 43, 1618-1626. [CrossRef]

22. Chen, F.; Wittkopf, S.K.; Khai Ng, P.; Du, H. Solar heat gain coefficient measurement of semi-transparent photovoltaic modules with indoor calorimetric hot box and solar simulator. Energy Build. 2012, 53, 74-84. [CrossRef]

23. Gueymard, C.A.; duPont, W.C. Spectral effects on the transmittance, solar heat gain, and performance rating of glazing systems. Sol. Energy 2009, 83, 940-953. [CrossRef]

24. Mazzali, U.; Ruggeri, P.; Zinzi, M.; Peron, F.; Romagnoni, P.; Daneo, A. Set-up and calibration by experimental data of a numerical model for the estimation of solar factor and Ug-value of building integrated photovoltaic systems. Energy Procedia 2015, 78, 2202-2207. [CrossRef]

25. CENELEC EN 674:2011. Glass in Building. Determination of Thermal Transmittance (U Value)—Guarded Hot Plate Method; British Standards Institution: London, UK, 2011.

26. CENELEC EN 673:2011. Glass in Building. Determination of Thermal Transmittance (U Value)-Calculation Method; British Standards Institution: London, UK, 2011.

27. CENELEC EN 50583-1:2016. Photovoltaics in Buildings_Part 1: BIPV Modules; British Standards Institution: London, UK, 2016.

28. CENELEC EN 410:2011. Glass in Building. Determination of Luminous and Solar Characteristics of Glazing; British Standards Institution: London, UK, 2011.

29. CIE 13.3:1995 International Commission on Illumination. Method of Measuring and Specifying Colour Rendering Properties of Light Sources; International Commission on Illumination: Vienna, Austria, 1995.

30. IEC 61646:2008. Thin-Film Terrestrial Photovoltaic (PV) Modules-Design Qualification and Type Approval; International Electrotechnical Commission (IEC): Geneva, Switzerland, 2008.

31. Piccolo, A.; Simone, F. Performance requirements for electrochromic smart window. J. Build. Eng. 2015, 3, 94-103. [CrossRef]

32. Assimakopoulos, M.N.; Tsangrassoulis, A.; Guarracino, G.; Santamouris, M. Integrated energetic approach for a controlable electrochromic device. Energy Build. 2004, 36, 415-422. [CrossRef] 
33. Jonsson, A.; Roos, A. Evaluation of control strategies for different smart window combinations using computer simulations. Sol. Energy 2010, 84, 1-9. [CrossRef]

34. Sibilio, S.; Rosato, A.; Scorpio, M.; Iuliano, G.; Ciampi, G.; Vanoli, G.; de Rossi, F. A Review of Electrochromic Windows for Residential Applications. Int. J. Heat Technol. 2016, 34, S481-S488. [CrossRef]

35. Sanders, H.; Podbelski, L. Dynamic façades: Solving the High Performance Building Challenge without Design Compromise. In Proceedings of the BEST4 Conference, Kansas City, MO, USA, 13-15 April 2015.

36. Hermelink, A.; von Manteuffel, B.; Grözinger, J. Minimum Performance Requirements for Window Replacement in the Residential Sector; Ecofys: Berlin, Germany, 2017.

37. Alamri, S.N. The temperature behavior of smart windows under direct solar radiation. Sol. Energy Mater. Sol. Cells 2009, 93, 1657-1662. [CrossRef]

38. Piccolo, A. Thermal performance of an electrochromic smart window tested in an environmental test cell. Energy Build. 2010, 42, 1409-1417. [CrossRef]

39. Baker, P.H.; van Dijk, H.A.L. PASLINK and dynamic outdoor testing of building components. Build. Environ. 2008, 43, 143-151. [CrossRef]

(C) 2018 by the authors. Licensee MDPI, Basel, Switzerland. This article is an open access article distributed under the terms and conditions of the Creative Commons Attribution (CC BY) license (http:/ / creativecommons.org/licenses/by/4.0/). 